\title{
Documentation of pharmacotherapeutic interventions of pharmacy students
}

\author{
Elicia D. KING, Mamie A. WILSON, Linh VAN, Frank S. EMANUEL.
}

\begin{abstract}
${ }^{*}$
During patient care rounds with the medical team, pharmacy students have made positive contributions for the benefit of the patient. However, very little has been documented regarding the impact these future healthcare professionals are making while on clinical rotations.

The objective of this study was to assess the impact that clinical interventions made by 6 th year pharmacy students had on overall patient outcome. Using a special program for a personal digital assistant (PDA), the students daily recorded the pharmacotherapeutic interventions they made. The interventions ranged from dosage adjustments to providing drug information. Data was collected over a 12-week period from various hospitals and clinics in the Jacksonville, Florida area.

In total, there were 89 pharmaceutical interventions performed and recorded by the students. Fifty interventions involved drug modification and fiftyfour interventions were in regards to drug information and consulting. Of the drug information and consulting interventions, 15 were drug modification.

This study shows the impact pharmacy students make in identifying, recommending, and documenting clinical pharmacotherapeutic interventions. Similar to pharmacists, pharmacy students can also have a positive contribution towards patient care.
\end{abstract}

Keywords: Students, Pharmacy, Medical Records. Treatment Outcome. United States.

\footnotetext{
*Elicia D. KING. PharmD. candidate. College of Pharmacy and Pharmaceutical Sciences, Florida Agricultural and Mechanical University. Jacksonville, FL (USA). Mamie A. WILSON. PharmD. candidate. College of Pharmacy and Pharmaceutical Sciences, Florida Agricultural and Mechanical University. Jacksonville, FL (USA).

Linh VAN. PharmD. candidate. College of Pharmacy and Pharmaceutical Sciences, Florida Agricultural and Mechanical University. Jacksonville, FL (USA). Frank S. EMANUEL. Pharm.D. FASHP. Division Director and Assistant Professor of Pharmacy Practice. College of Pharmacy and Pharmaceutical Sciences, Florida Agricultural and Mechanical University. Jacksonville, FL (USA).
}

\begin{abstract}
RESUMEN
Durante las rondas de atención a pacientes con el equipo médico, los estudiantes de farmacia realizan contribuciones positivas en beneficio del paciente. Sin embargo, se ha documentado muy poco en relación al impacto de estos futuros profesionales de la salud en las rotaciones clínicas.

El objetivo de este estudio fue evaluar el impacto que las intervenciones clínicas hechas por estudiantes de sexto año tenían sobre los resultados generales del paciente.

Utilizando un programa especial para PDA, los estudiantes registraban diariamente las intervenciones farmacoterapéuticas que hacían. Las intervenciones iban desde ajustes de dosis a provisión de información de medicamentos. Los datos se recogieron durante 12 meses de varios hospitales y clínicas en el área de Jacksonville, Florida.

En total, hubo 89 intervenciones farmacéuticas realizadas y registradas por los estudiantes. Cincuenta intervenciones involucraban modificación de medicamento y 54 intervenciones estaban relacionadas con la información de medicamentos y consultas. De estas informaciones de medicamentos y consultas, 15 fueron modificaciones de medicamentos.

Este estudio muestra el impacto de los estudiantes de farmacia al identificar, recomendar y documentar intervenciones clínicas farmacoterapéuticas. Al igual que los farmacéuticos, los estudiantes de farmacia pueden tener una contribución positiva en la atención al paciente.
\end{abstract}

Palabras clave: Estudiantes de farmacia. Historial médico. Resultados del tratamiento. Estados Unidos.

\section{(English)}

\section{INTRODUCTION}

In the case of the majority of patients, the pharmacist is the last health care professional that they have the opportunity to consult with in regards to their medication. When involved in patient care, the pharmacist can make recommendations, counsel patients, and, together with physicians, provide the most optimal care. Prior studies have proven the presence of a pharmacist in both clinical and hospital settings have led to increased positive outcomes for patients. $^{1-4}$ 
However, until recently, there was minimal evidence as to the impact of pharmacy students on patient care. ${ }^{5}$ Pharmacy students spend a minimum of three years in didactic training, and one year in practical rotations preparing them for aiding in patient care. This study was conducted to investigate the impact of these students and their contributions to patient care.

Due to all of the new technological advances available, it has become easier than ever to document patient interventions. Specifically, the use of personal digital assistants (PDAs) to record pharmacotherapeutic interventions has made the documentation process more efficient. In this study, we used PDAs to document student interventions.

The objective of this study is to document pharmacotherapeutic interventions of sixth year Doctor of Pharmacy students using a personal digital assistant (PDA). The study will assess the impact of clinical interventions made by these students on overall patient care.

\section{METHODS}

\section{Study Design}

This was a prospective, observational study conducted at various local hospitals and clinics approved by Florida Agricultural and Mechanical University College of Pharmacy and Pharmaceutical Sciences (FAMU) in the Jacksonville Pharmacy Practice Division. Data was collected and gathered by sixth year doctor of pharmacy candidates from FAMU over a period of 12 weeks. Students were selected to participate in the study based on the type of site in which they were currently doing their clinical rotations. Eligible rotations included internal medicine, ambulatory care, pediatrics, and any clinical electives where patient interaction was involved.

The information was recorded on MedKeeper's PDA intervention tracking program, RxRounds ${ }^{\mathrm{TM}}$. Interventions were recorded by the students on a daily basis, and captured through medical chart review, clinical rounds, drug information questions, and/or patient counseling encounters.

\section{Evaluation}

Several types of pharmacotherapeutic interventions were recorded. The interventions were divided into two categories: drug modification and drug information. The drug modification category included prevention of adverse effects, drug substitutions, formulation/route changes, and interval modifications. The drug information category consisted of any general consults, including but not limited to pharmacokinetic consults, patient counseling, or any general drug information.

\section{Inclusion Criteria}

Interventions were included if they were within the categories of prevention of adverse effects, drug substitutions, formulation/route changes, interval modifications, pharmacokinetic consults, drug information, or drug/lab/food interactions. Interventions were also included if they were documented on the PDAs within one day of the intervention, and were made solely by the sixth year PharmD candidate the PDA was issued to.

\section{Exclusion Criteria}

Interventions were excluded if they were not made within the 12 weeks the study was conducted. Other exclusion criteria included any interventions made outside of the approved rotation or without the knowledge or approval of the pharmacist preceptor.

\section{Program Design}

The PDA program used was MedKeeper's intervention tracking program, RxRounds ${ }^{\mathrm{TM}}$. This program allowed students to input interventions by date, location, and, preceptor at time of rotation. To prevent a breach in patient confidentiality, patients' names and social security numbers were omitted. With this program, students documented the type of intervention proposed, what the suspected outcome would be, and if anything was avoided. Lastly, the student documented whether the intervention was accepted or rejected by their preceptor or attending physician. At the end of 4 weeks, the PDAs were returned, and the data was uploaded to the computer database.

\section{RESULTS}

At the end of twelve weeks, there were eighty-nine total interventions documented on the RxRounds program. The program also tracked the number of hours spent for each intervention category. In what were considered drug information interventions, over 13.25 hours were recorded. An overwhelming amount of these hours (55\%) were spent giving consults in anticoagulation clinics (table 1).

\begin{tabular}{|l|c|}
\hline \multicolumn{2}{|c|}{ Table 1: Length of Drug Information Interventions. } \\
\hline \multicolumn{1}{|c|}{ Type } & Number of Hours \\
\hline Anticoagulation Consult & 7.33 \\
\hline Compliance counseling & 0 \\
\hline Discharge counseling & 0.33 \\
\hline Dosing Consult & 0.5 \\
\hline Drug Information Question & 3 \\
\hline Drug Therapy Review & 0.67 \\
\hline Patient counseling & 0 \\
\hline Patient Drug History & 0 \\
\hline Pharmacokinetics Consult & 1.42 \\
\hline Total & 13.25 \\
\hline
\end{tabular}

Fifty interventions involved drug modification which was $56.1 \%$ of the eighty nine total interventions (table 2). The most common of the drug modification interventions was drug initiation. Many of these initiations were needed to avoid particular adverse effects. Others were substitutions for more financially sound but therapeutically equivalent medications. Still others were drug substitutions to avoid an adverse reaction.

The majority of the documented interventions were from the drug information category of which there were 54 or $60.7 \%$. Of these interventions, $52 \%$ involved some form of consulting. The most common consults, $31 \%$ were given in the anticoagulation clinics. (table 3 ) Of the eighty-nine 
total interventions, only two $(2.2 \%)$ were rejected by the preceptors.

\begin{tabular}{|c|c|c|}
\hline \multicolumn{3}{|c|}{ Table 2: Quantity of Drug Modification Interventions } \\
\hline Type & Quantity & Percentage \\
\hline Drug Initiation & 19 & 38 \\
\hline Drug Substitution & 10 & 30 \\
\hline Drug Discontinuation & 4 & 8 \\
\hline Change in Interval & 11 & 22 \\
\hline Change in Duration & 1 & 2 \\
\hline Total & 50 & 100 \\
\hline
\end{tabular}

\begin{tabular}{|l|c|}
\hline $\begin{array}{l}\text { Table 3: Drug Information } \\
\text { Interventions }\end{array}$ & Pharmacotherapeutic \\
\hline \multicolumn{1}{|c|}{ Interventions } & Quantity \\
\hline Anticoagulation Consult & 17 \\
\hline Compliance Counseling & 5 \\
\hline Discharge Counseling & 4 \\
\hline Dosing Consult & 3 \\
\hline Drug Information Question & 13 \\
\hline Drug Therapy Review & 3 \\
\hline Patient Counseling & 1 \\
\hline Patient Drug History & 7 \\
\hline Pharmacokinetics Consult & 54 \\
\hline \multicolumn{2}{|c|}{ Total }
\end{tabular}

\section{DISCUSSION}

In a general sense, the mere involvement of pharmacists on health care teams has shown an increase in patient compliance, decreased drug cost, and increase in prevention of adverse effects can be achieved. ${ }^{5}$ In a study conducted by Gattis et al., the addition of a clinical pharmacist alone to a heart failure management team resulted in a decrease in all cause mortality and heart failure. ${ }^{6}$ Within the last few years, the impact of future pharmacists, sixth year PharmD candidates, has been investigated.

In July 2004, Freml et al published a study in which pharmacy students actually made significantly more total recommendations than pharmacists in their lowa study. ${ }^{7}$ Even though in this study, pharmacy students were not compared to pharmacist, it is obvious that pharmacy students can make valid and justifiable suggestions toward the benefit of patient care. A strong pharmacy student impact was seen in the anticoagulation clinic, where some $31 \%$ of drug information interventions were recorded. From dosage modification to recognizing drug interactions, pharmacy students had the ability to make valid and worthwhile interventions.

This study also showed that pharmacy students were knowledgeable in a variety of aspects. Students were consulted on a variety of issues, from pharmacokinetics to dosing. Students also provided a significant amount of consultation, with over 16 hours of interventions devoted to some form of patient counseling.
In $38 \%$ of the drug modifications, a drug was initiated. In many cases drugs were substituted to either avoid a potential adverse effect or to decrease cost. This reinforces the fact that pharmacy students are aware of the many facets of drug therapy. The majority of drug interval changes were in regards to antibiotics, with pharmacy students recognizing that different illnesses require different lengths of treatments.

In regards to the PDAs, prior studies have also shown the usefulness of PDAs in documenting patient interventions. Similar to what Collins and Bosinski concluded in their studies of PDAs usefulness in pharmacy interventions, the PDAs did increase the level of efficiency. ${ }^{8}$ The small size of the PDAs allowed the students to carry them in their pockets, which consequently made it easier for them to document the interventions on a daily basis. Often times, students documented the intervention right after it happened, versus waiting until later. This led to more reliable data, with students putting in what really happened versus what they "thought" or "remembered" happening.

This is compared to before, where interventions were recorded on numerous sheets of paper and filed in various places. This process was both tedious and time consuming, thus avoided by many practitioners. In addition, it was helpful that whenever a change was needed in the RxRounds program, it could be achieved by simply changing the programs and updating the PDAs.

However, even with technological advances, human error cannot be ignored. On several occasions students commented they forgot how to use the program or were unclear with what category their intervention should have been placed. At that point, it was noted that maybe there were not enough options from which the students could choose. On other occasions, there were students who said their intervention fit into several categories

With only $2.2 \%$ of the pharmacy students' recommendations being rejected by practitioners, this implies that practitioners seem to be receptive to pharmacy students and their input.

\section{CONCLUSION}

This study shows the significant impact pharmacy students have in identifying, recommending, and documenting clinical pharmacotherapeutic interventions. Pharmacy students are knowledgeable in many areas, which make them well equipped to effect patient care. This study proves, just as physicians, nurse, and pharmacists can significantly improve patient care, so can pharmacy students.

1. Leape LL, Cullen DJ, Clapp MD, et al. Pharmacist Participation on Physician Rounds and Adverse Drug Events in the Intensive Care Unit. JAMA 1999;282:267-270.

2. Montazeri M, Cook DJ. Impact of a Clinical Pharmacist in a Multidisciplinary Intensive Care Unit. Crit Care Med 1994;22(6):1044-8. 
3. Hanlon JT, Weinberger M, Samsa GP. A Randomized, Controlled Trial of a Clinical Pharmacist Intervention to Improve Inappropriate Prescribing in Elderly Outpatients with Polypharmacy. Am J Med 1999;100(4):428-37.

4. Keely JL; American College of Physicians-American Society of Internal Medicine. Pharmacist scope of practice.. Ann Intern Med. 2002;136(1):79-85.

5. McMullin ST, Hennenfent JA, Ritchie DJ, Huey WY, Lonergan TP, Schaiff RA, Tonn ME, Bailey TC. A Prospective, Randomized Trial to Assess the Cost Impact of Pharmacist-Initiated Interventions. Arch Intern Med. 1999;159(19):2306-9.

6. Gattis WA, Hasselblad V, Whellan DJ, O'Connor CM. Reduction in heart failure events by the addition of a clinical pharmacist to the heart failure management team: results of the Pharmacist in Heart Failure Assessment Recommendation and Monitoring (PHARM) Study. Arch Intern Med. 1999;159(16):1939-45.

7. Freml JM, Farris KB, Fang G, Currie J. lowa Priority's Brown Bag Medication Reviews: A Comparison of Pharmacy Students and Pharmacists. Am J Pharm Educ 2004;68(2):article 50.

8. Collins MF. Measuring Performance Indicators in Clinical Pharmacy Services with a Personal Digital Assistant. Am J Health-Syst. Pharm 2004;61:498-501.

9. Bosinski TJ, Campbell L, Schwartz S. Using a Personal Digital Assistant to Document Pharmacotherapeutic Interventions. Am J Health Syst Pharm 2004;61(9):931-4. 